\title{
SISTEMAS CONSTRUTIVOS INDUSTRIALIZADOS NOS CURSOS DE GRADUAÇÃO EM ENGENHARIA CIVIL E ARQUITETURA DO BRASIL
}

DOI: 10.15552/2236-0158/abenge.v34n2p53-60

Ana Beatriz de Figueiredo Oliveira, ${ }^{1}$ Henor Artur de Souza ${ }^{2}$

\begin{abstract}
RESUMO
Sistemas construtivos industrializados se caracterizam como uma alternativa eficiente à construção in loco. No entanto, seu uso no mercado brasileiro é pequeno se comparado ao seu potencial. Uma das razões dessa situação está na qualidade do ensino superior na questão da formação do aluno em construção industrializada. Este artigo tem como objetivo investigar a abordagem de sistemas construtivos industrializados nas matrizes curriculares dos cursos de graduação em engenharia civil e arquitetura no Brasil. Como método de pesquisa, utiliza-se a revisão bibliográfica com a conceituação do tema da industrialização da construção civil e a análise das matrizes curriculares de 284 universidades brasileiras, entre públicas e privadas. Como resultado, observou-se que o ensino sobre sistemas industrializados é deficiente ou até mesmo inexistente. Apenas $8 \%$ das faculdades de engenharia civil e $15 \%$ das faculdades de arquitetura possuem pelo menos uma disciplina exclusiva e obrigatória sobre esse tema. Desse modo, vê-se a necessidade de aperfeiçoar o ensino superior nas áreas de engenharia civil e arquitetura com a introdução de disciplinas sobre tecnologias construtivas voltadas à industrialização da construção.
\end{abstract}

Palavras-chave: Construção industrializada; ensino em engenharia civil; ensino em arquitetura e urbanismo.

\section{ABSTRACT \\ INDUSTRIALIZED BUILDING SYSTEMS IN BRAZILIAN UNDERGRADUATE COURSES OF CIVIL ENGINEERING AND ARCHITECTURE}

Industrialized building systems are efficient alternatives to conventional systems. In spite of this, its use is small in the Brazilian construction market compared to the potential of the system. One of the reasons for that is the quality of teaching industrialized construction in superior education. This paper aims to investigate the approach to the industrialized building systems in programs of undergraduate courses on civil engineering and architecture in Brazil. As a research method, it was made a literature review with theoretical context of industrialization and an analysis of the curriculums of 284 Brazilian universities. The result found on this research was a deficient or even non-existent approach of industrialized building systems in the universities analyzed. Only $8 \%$ of civil engineering colleges and 15\% of architecture colleges have at least one exclusive and compulsory discipline that includes this subject. Therefore, it is necessary to improve programs of civil engineering and architecture colleges with the insertion of disciplines that deal with the issue of industrialized building technologies.

Keywords: Industrialized building system; education in civil engineering; education in architecture. INTRODUÇÃO

1 Arquiteta e urbanista, Mestre em Engenharia Civil - Universidade Federal de Ouro Preto - Campus Morro do Cruzeiro; anabeatrizfig@yahoo.com.br

2 Professor, Doutor, Escola de Minas - Universidade Federal de Ouro Preto - Campus Morro do Cruzeiro; henorster@gmail.com 


\section{INTRODUÇÃO}

Diante da grande demanda por habitações, do crescimento do setor da construção civil e da busca por construções com menor impacto ambiental, os sistemas construtivos industrializados seriam uma opção lógica na escolha de profissionais e clientes para seus projetos. No entanto, no Brasil, grande parte das edificações são construídas com sistemas construtivos convencionais, ou seja, aqueles em que os processos são realizados principalmente dentro do canteiro de obras (BATISTA; GHAVAMI, 2005).

O cenário atual no Brasil se mostra propenso à ampliação e ao desenvolvimento do setor da pré-fabricação. Um fato é a grande demanda por habitações, principalmente para famílias de baixa renda, do programa social criado pelo governo federal "Minha Casa Minha Vida" (NRE, 2014). O país também está passando por grandes transformações de infraestrutura urbana, que são um reflexo da realização de importantes eventos internacionais, como é o caso das Olimpíadas, em 2016, e foi o caso da Copa das Confederações, em 2013, e da Copa do Mundo, em 2014. Além disso, existem diversos projetos auxiliares de obras viárias e urbanas, como é o caso do projeto Porto Maravilha, na cidade do Rio de Janeiro, que visa reestruturar a região portuária da cidade, atraindo, assim, novos empreendimentos (COMA, 2011).

No entanto, o mercado da construção civil ainda não absorveu todo o potencial da pré-fabricação (CBCA; ABCEM, 2014). Essa realidade brasileira pode ter como uma das causas a qualidade do ensino superior de engenharia civil e arquitetura. Esse artigo é uma continuação da pesquisa apresentada no XLII Congresso Brasileiro de Educação em Engenharia (OLIVEIRA; SOUZA, 2014) e tem como objetivo investigar a abordagem de sistemas construtivos industrializados nas matrizes curriculares desses cursos nas universidades brasileiras. Como metodologia, utiliza-se a revisão bibliográfica que apresenta o conceito de industrialização da construção civil; empreende-se, ainda, a análise das matrizes curriculares dos cursos de engenharia civil e arquitetura de 284 universidades brasileiras, que possuem os dois cursos simultaneamente.

\section{INDUSTRIALIZAÇÃO NA CONSTRUÇÃO CIVIL}

A industrialização na construção civil pode ser definida como a utilização de componentes produzidos dentro de um ambiente de fábrica e transportados ao canteiro de obras para montagem final. Também está presente na industrialização a característica de padronizar os elementos construtivos e os próprios processos e métodos de construção (BILDSTEN, 2013; GIBB, 2001). Assim, a construção industrializada pode ser vista como uma alternativa ao sistema convencional e possui muitas vantagens sobre ele, como melhor qualidade dos componentes pré-fabricados, menores custos e prazos de construção, menor desperdício de materiais e integração entre o projeto arquitetônico e a construção em si (TAM et al., 2007).

O uso de componentes pré-fabricados na construção civil teve como objetivo inicial buscar uma maneira mais econômica de construir. As indústrias produziram milhões de elementos idênticos, com a finalidade de alcançar algumas metas, como a padronização, especialização, sincronização, concentração, maximização e centralização. Ao longo dos anos, o foco da indústria passou a ser a personalização dos produtos, para lidar com as necessidades individuais dos clientes (BRANDÃO; HEINECK, 2007). Assim, uma questão importante no processo de produção é encontrar uma maneira de atender à demanda dos clientes da forma mais eficiente possível, pois, quanto mais industrializado é o processo, menor é o grau de personalização e flexibilidade da produção (JONSSON; RUDBERG, 2013).

Com o intuito de adaptar a industrialização às exigências tanto das edificações quanto dos clientes, a construção passou de um sistema fechado para um sistema aberto. $\mathrm{O}$ primeiro está relacionado a um sistema rígido, fato que exige que os projetistas trabalhem com um produto muitas vezes incompatível com a arquitetura. $\mathrm{O}$ segundo é baseado na utilização de componentes industrializados que podem ser produzidos por diferentes empresas e garante maior flexibilidade aos projetos, como se pode deduzir pela observação do Quadro 1. 
Quadro 1 - Questões fundamentais para as mudanças tecnológicas da construção industrializada.

\begin{tabular}{lll}
\multicolumn{1}{c}{ Tendências } & \multicolumn{1}{c}{ Mudanças } & \multicolumn{1}{c}{ Resultados } \\
\hline $\begin{array}{l}\text { Técnicas de produção de } \\
\text { componentes. }\end{array}$ & $\begin{array}{l}\text { Flexibilização dos processos de } \\
\text { produção. }\end{array}$ & Séries pequenas e diversificadas. \\
\hline Coordenação modular. & Menos acadêmica e mais prática. & $\begin{array}{l}\text { De ferramenta de projeto a suporte da } \\
\text { produção. Do módulo dimensional ao } \\
\text { módulo do objeto. }\end{array}$ \\
\hline $\begin{array}{l}\text { Mudanças de paradigmas } \\
\text { básicos. }\end{array}$ & $\begin{array}{l}\text { De produtores de pré-fabricados } \\
\text { e construtores a consumidores de } \\
\text { componentes construtivos. }\end{array}$ & $\begin{array}{l}\text { A indústria (química, de vidro, de } \\
\text { gesso, de isolantes...) invade o setor da } \\
\text { construção civil. }\end{array}$ \\
\hline $\begin{array}{l}\text { Maior influência da indústria no } \\
\text { custo final de produção. }\end{array}$ & $\begin{array}{l}\text { Concorrência de materiais, técnicas e } \\
\text { componentes. }\end{array}$ & $\begin{array}{l}\text { O valor adicionado de origem industrial } \\
\text { supera o valor dos sistemas fechados de } \\
\text { pré-fabricação pesada. }\end{array}$ \\
\hline $\begin{array}{l}\text { Fim de um falso dilema: } \\
\text { arquitetura } x \text { indústria. }\end{array}$ & $\begin{array}{l}\text { Equipes de trabalho } \\
\text { multidisciplinares. }\end{array}$ & $\begin{array}{l}\text { Nova disciplina: Arquitetura } \\
\text { Industrializada. }\end{array}$ \\
\hline
\end{tabular}

Adaptado de SALAS (2008).

No entanto, para que a utilização de sistemas construtivos industrializados seja eficiente, é necessário aplicar uma visão sistêmica e global à construção (RIBAS, 2006). A decisão pelo uso desses sistemas deve partir da concepção do projeto, de forma que os componentes construtivos disponibilizados pelas indústrias estejam integrados ao projeto arquitetônico. Além disso, é necessário estudar de que maneira esses componentes se comportarão nas respectivas etapas da obra, que devem ser planejadas também no projeto, pois a montagem no canteiro de obras não permite adaptações nem ajustes. No entanto, no mercado nacional, poucos profissionais estão realmente aptos a trabalhar com a construção industrializada, sejam eles arquitetos ou engenheiros (SANTIAGO, 2008). Portanto, esse tipo de construção apresenta características muito particulares e que devem ser entendidas para que seus benefícios possam ser aproveitados.

\section{ANÁLISE DAS MATRIZES CURRICULARES}

A universidade é responsável pela formação dos futuros profissionais que atuarão no mercado da construção civil. Dessa forma, para que se possa pensar em ampliar a utilização de sistemas construtivos industrializados no Brasil, devese, primeiro, trabalhar para que esse sistema seja difundido na base de ensino.
Em 2002, o Ministério da Educação (MEC) instituiu as "Diretrizes Curriculares Nacionais do Curso de Graduação em Engenharia”, que abordam todas as modalidades da área, inclusive a engenharia civil. Nesse documento, é descrito o perfil do futuro profissional como tendo:

formação generalista, humanista, crítica e reflexiva, capacitado a absorver e desenvolver novas tecnologias, estimulando a sua atuação crítica e criativa na identificação e resolução de problemas, considerando seus aspectos políticos, econômicos, sociais, ambientais e culturais, com visão ética e humanística, em atendimento às demandas da sociedade (BRASIL, 2002).

Além disso, o MEC institui que o curso superior em engenharia deve dotar o futuro profissional de algumas habilidades e competências, entre elas, a de poder "desenvolver e/ou utilizar novas ferramentas e técnicas” (BRASIL, 2002).

No caso da arquitetura e do urbanismo, o MEC determina, nas diretrizes curriculares nacionais, que as instituições de ensino deverão:

assegurar a formação de profissionais generalistas, capazes de compreender e traduzir as necessidades de indivíduos, grupos sociais e comunidade, com relação à concepção, à organização e à construção do espaço interior e exterior, abrangendo o urbanismo, a edificação, o paisagismo, bem como a conservação e a valorização do patrimônio construído, 
a proteção do equilíbrio do ambiente natural e a utilização racional dos recursos disponíveis (BRASIL, 2010).

Além disso, as ações pedagógicas do curso de arquitetura e urbanismo deverão seguir alguns princípios, entre eles:

o uso da tecnologia em respeito às necessidades sociais, culturais, estéticas e econômicas das comunidades (BRASIL, 2010).

Em relação aos sistemas construtivos, o MEC prevê que o aluno desse curso possa adquirir, dentro da instituição de ensino, as seguintes habilidades e competências:

os conhecimentos especializados para o emprego adequado e econômico dos materiais de construção e das técnicas e sistemas construtivos, para a definição de instalações e equipamentos prediais, para a organização de obras e canteiros e para a implantação de infraestrutura urbana; [...] a compreensão dos sistemas estruturais e o domínio da concepção e do projeto estrutural, tendo por fundamento os estudos de resistência dos materiais, estabilidade das construções e fundações (BRASIL, 2010).

Embora as universidades sejam obrigadas a seguir as diretrizes para definir os programas dos cursos, o MEC não define regras mais específicas relacionadas à racionalização e industrialização do processo construtivo. Dessa forma, as instituições podem decidir se vão inserir ou não esses tópicos nas matrizes curriculares dos cursos de engenharia civil e arquitetura.

Método de pesquisa

Para avaliar de que maneira o tema da construção industrializada é abordado, no Brasil, dentro dos cursos superiores de engenharia civil e de arquitetura e urbanismo, analisaram-se as matrizes curriculares dos cursos em questão de universidades públicas e privadas distribuídas em todas as regiões do país. No Brasil, existem, atualmente cadastradas no MEC, 347 faculdades de arquitetura e urbanismo e 572 faculdades de engenharia civil, sendo que 284 universidades possuem os dois cursos simultaneamente (BASIL, 2015). Para essa pesquisa, foram selecionadas as instituições de ensino que oferecem ambos os cursos.
Essa análise baseou-se nos programas e ementas das disciplinas disponibilizadas no site oficial das instituições. Para uma primeira análise, foram selecionadas disciplinas que possuíam, no título, termos como "construção industrial”, "construção industrializada”, "racionalização” ou "pré-fabricação”. Quando esses termos não existiam em nenhum título das disciplinas, foram selecionadas aquelas que tratam de projeto arquitetônico ou de sistemas construtivos, com termos como "tecnologia da construção", "sistemas estruturais", "projeto", "ateliê", "estruturas metálicas” ou "concreto pré-moldado".

Em uma segunda análise, observou-se a ementa das disciplinas selecionadas, com o intuito de avaliar se realmente possuíam em seu programa o assunto da construção industrializada e se ele era passado aos alunos de forma abrangente, ou seja, considerando o processo de fabricação, projeto e construção, ou apenas de maneira específica, ou seja, tratando apenas de características e cálculos de um material determinado. Para essa pesquisa, somente foram consideradas as disciplinas que abordavam a construção industrializada de forma abrangente, pois o foco deste trabalho é a construção industrializada como um todo, independentemente do material utilizado.

A partir dos resultados da segunda análise, realizou-se uma classificação dessas disciplinas. Elas foram classificadas em dois grupos que indicam a importância do tema da industrialização na disciplina como um todo. As classificações utilizadas foram: disciplinas exclusivas, que são aquelas que abordam exclusivamente o tema da construção industrializada; e disciplinas não exclusivas, que são aquelas que abordam o tema da construção industrializada apenas como um tópico dentro do programa. Cada uma das classificações foi subdividida em disciplina obrigatória ou optativa. A primeira representa as disciplinas que fazem parte da grade curricular obrigatória do curso e a segunda aquelas disciplinas que não fazem parte da grade curricular obrigatória do curso, ou seja, durante sua formação, os alunos podem optar por cursá-la ou não.

\section{Resultados: Engenharia Civil}

No caso do curso de engenharia civil, dentre as 284 universidades pesquisadas, 88 puderam ser 
avaliadas. As demais não disponibilizam em seu site a matriz curricular ou as ementas das disciplinas do curso.

Dessas 88 universidades analisadas, somente quinze possuem disciplinas exclusivas, com o tema da construção industrializada, sendo que sete possuem disciplinas obrigatórias, e oito, disciplinas optativas. Isso representa $8 \%$ e $9 \%$, respectivamente.

Em relação às disciplinas não exclusivas, observou-se que 27 instituições possuem esse tipo de disciplina de forma obrigatória e duas de forma optativa, o que equivale a $31 \%$ e $2 \%$, respectivamente. Pode-se constatar, ainda, que 44 universidades não possuem disciplinas sobre construção industrializada em sua matriz curricular, ou seja, $50 \%$ delas (Gráfico 1).

\section{Gráfico 1: Resultado da análise das matrizes} curriculares dos cursos de engenharia civil.

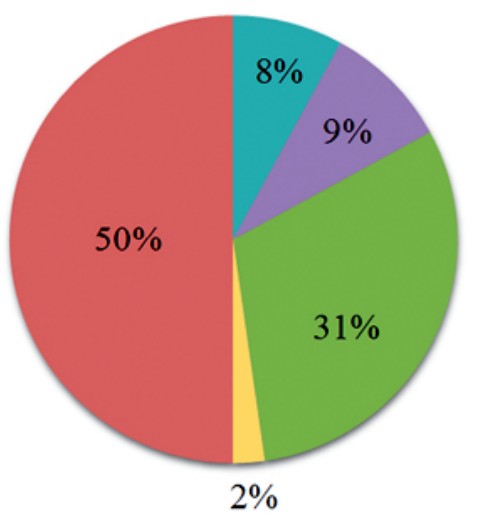

\section{LEGENDA}

- Disciplinas exclusivas - Obrigatórias

- Disciplinas exclusivas - Optativas

n Disciplinas não exclusivas - Obrigatórias

Disciplinas não exclusivas - Optativas

não possuem

Em relação às 44 universidades que possuem disciplinas sobre industrialização, $70 \%$ delas possuem apenas uma disciplina na sua grade curricular, $23 \%$ possuem duas disciplinas e apenas $7 \%$ possuem mais de duas disciplinas (Gráfico 2). Entre os termos utilizados nas ementas para adjetivar os sistemas industrializados se destacaram "especiais", "alternativos" e "não convencionais", o que indica que esse tema é tratado de forma secundária dentro das faculdades de engenharia civil analisadas.

Gráfico 2: Número de disciplinas sobre construção industrializada nos cursos de engenharia civil.

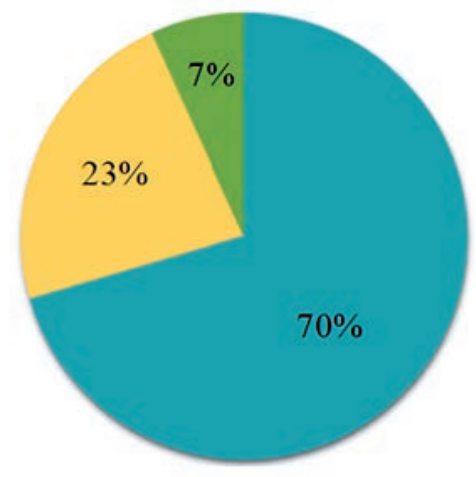

\section{LEGENDA}

$$
\begin{aligned}
& =1 \text { disciplina } \\
& =2 \text { disciplinas } \\
& =\text { Mais de } 2 \text { disciplinas }
\end{aligned}
$$

\section{Resultados: Arquitetura e Urbanismo}

Em relação ao curso de arquitetura e urbanismo, dentre as 284 universidades pesquisadas, $77 \mathrm{pu}$ deram ser avaliadas. As outras instituições não possuem em seu site a matriz curricular ou as ementas das disciplinas do curso.

Das 77 universidades avaliadas, apenas dezoito delas possuem disciplinas exclusivas sobre construção industrializada, sendo que doze instituições oferecem disciplinas obrigatórias e seis oferecem disciplinas optativas, o que representa $15 \%$ e $8 \%$, respectivamente.

Outras 33 instituições possuem disciplinas não exclusivas, sendo todas elas disciplinas obrigatórias, o que equivale a $43 \%$ do total. Pode-se perceber, ainda, que 26 universidades não possuem, em sua matriz curricular, disciplinas que abordam o tema da industrialização, ou seja, 43\% delas (Gráfico 3).

No caso das 51 universidades que possuem disciplinas sobre construção industrializada, 63\% delas possuem apenas uma disciplina na sua grade curricular, $21 \%$ possuem duas disciplinas e $16 \%$ possuem mais de duas disciplinas (Gráfico 4). Entre os termos que explicam os sistemas industrializados, nas ementas, se destacaram "alternativos", 
"especiais", "não usuais" e "não convencionais", indicando esse sistema como secundário, comparado com os demais, assim como foi visto nas faculdades de engenharia civil pesquisadas.

Gráfico 3: Resultado da análise das matrizes curriculares dos cursos de arquitetura e urbanismo.

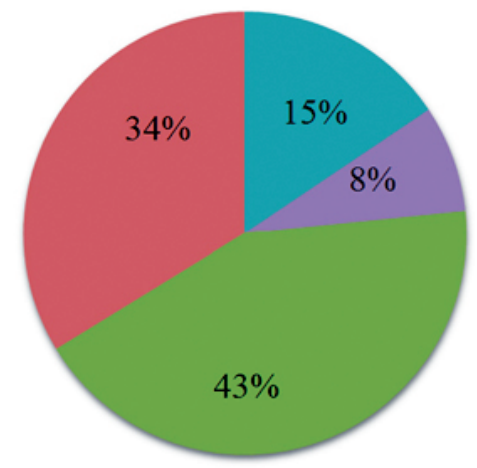

\section{LEGENDA}

- Disciplinas exclusivas - Obrigatórias

- Disciplinas exclusivas - Optativas

- Disciplinas não exclusivas - Obrigatórias

não possuem

Gráfico 4: Número de disciplinas sobre construção industrializada nos cursos de arquitetura e urbanismo

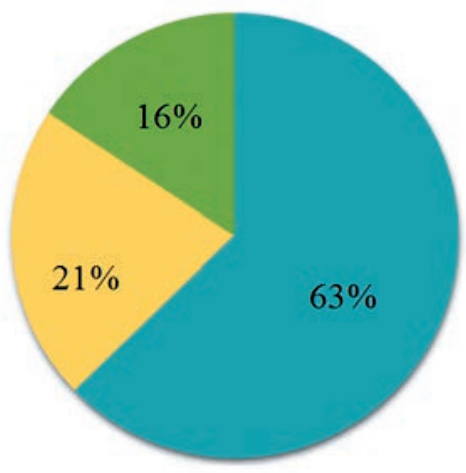

\section{LEGENDA}

$$
\begin{aligned}
& =1 \text { disciplina } \\
& =2 \text { disciplinas } \\
& =\text { Mais de } 2 \text { disciplinas }
\end{aligned}
$$

\section{CONCLUSÕES}

Com a análise das matrizes curriculares dos cursos de engenharia civil e de arquitetura e urbanismo, observou-se que é ineficiente a abor- dagem do tema da construção industrializada nos cursos pesquisados. A maior parte das disciplinas encontradas nesses cursos possuem o tema apenas como um tópico de uma disciplina voltada a outro assunto ou então são optativas.

Apenas 8\% das instituições de ensino de engenharia civil possuem o tema da construção industrializada em pelo menos uma disciplina exclusiva e obrigatória na matriz curricular. E, no caso do curso de arquitetura e urbanismo, esse número é de $15 \%$. Além disso, no universo pesquisado, o número de universidades que não tratam do tema em nenhuma disciplina é grande, sendo $50 \%$ no caso da engenharia civil e 34\% em arquitetura e urbanismo.

Quando acontece a abordagem da industrialização da construção civil nos cursos de engenharia civil e de arquitetura e urbanismo, existe a predominância de apenas uma disciplina relacionada ao tema inserida na matriz curricular. Além disso, a classificação dos sistemas industrializados como "alternativos" ou "especiais" reforça e insere no conhecimento dos alunos a ideia de que são sistemas estruturais secundários. Isso reforça a cultura da não utilização das construções pré-fabricadas nos projetos comuns, restringindo-as aos casos em que o sistema convencional não é viável.

Devido à falta de resoluções nacionais que especifiquem o assunto da industrialização da construção dentro das diretrizes de cada curso, a opção por incluí-lo na matriz curricular parte do interesse de cada instituição. Dessa forma, muitos estudantes se formam sem que tenham contato com algum tipo de construção que não seja a convencional, baseada na alvenaria de tijolos cerâmicos e concreto armado moldado in loco.

O Brasil possui grande potencial para que sistemas industrializados sejam empregados nos diversos tipos de construções. Isso pode ser observado a partir da expressiva produção siderúrgica, diversas indústrias voltadas à construção civil, além de campo de pesquisa e formação profissional eficiente, com universidades instaladas por todo o território. Apesar disso, ainda faltam incentivos e informações mais difundidas desses sistemas, de forma que eles possam se 
tornar escolhas reais no mercado da construção civil.

Com os resultados desta pesquisa, observou-se que é necessário investir no campo de formação superior, nos cursos de engenharia civil e de arquitetura e urbanismo no Brasil. Os futuros profissionais da construção civil precisam ter contato com os sistemas industrializados dentro das universidades, para que eles tenham conhecimentos suficientes para propor esse tipo de construção aos seus clientes. Além disso, é importante alterar a maneira com que o tema da industrialização é passado aos alunos. Cada projeto vai demandar um sistema construtivo que se adapte melhor às necessidades tanto do cliente quanto técnicas e da proposta do arquiteto. Portanto, não se deve classificar, nas disciplinas, os sistemas industrializados como sendo "alternativos", "especiais" ou "não convencionais". A partir do momento em que o profissional possui formação e conhecimento suficientes, cabe a ele identificar e propor o melhor processo construtivo para cada caso.

\section{AGRADECIMENTOS}

Os autores agradecem ao apoio financeiro da CAPES e da FAPEMIG.

\section{REFERÊNCIAS}

BATISTA, Eduardo de Miranda; GHAVAMI, Khosrow. Development of Brazilian steel construction. Journal of Constructional Steel Research, v. 61, n. 8, p. 1.0091.024, ago. 2005.

BILDSTEN, Louise. Buyer-supplier relationships in industrialized building. Construction Management and Economics, v. 32, n. 1-2, p.146-159, 2013.

BRANDÃO, Douglas Queiroz; HEINECK, Luiz Fernando Mählmann. Estratégias de flexibilização de projetos residenciais iniciadas na década de 1990 no Brasil: tão somente um recurso mercadológico? Ambiente Construído, v. 7, n. 4, p. 71-87, 2007.

CBCA; ABCEM. Perfil dos fabricantes de estruturas de aço: Resumo Executivo - Pesquisa 2014. São Paulo: O Nome da Rosa Editora, 2014. Disponível em: $<$ http://www.cbca-acobrasil.org.br/ site/publicacoes-estrutura-de-aco.php >. Acesso em: 23 fev. 2014.
COMA, Mauro Castro. Del sueño olímpico al proyecto Porto Maravilha: el "eventismo" como catalizador de la regeneración a través de grandes proyectos urbanos. URBE - Revista Brasileira de Gestão Urbana, Curitiba, v. 3, n. 2, p. 211-227, jul./dez. 2011.

GIBB, Alistair G. F. Standardization and Pre-assembly-distinguishing myth from reality using case study research. Construction Management and Economics, v. 19, n. 3, p. 307-315, 2001.

JONSSON, Henric; RUDBERG, Martin. Classification of production systems for industrialized building: a production strategy perspective. Construction Management and Economics, v. 32, n. 1-2, p. 53-69, 2013.

BRASIL. MINISTÉRIO DA EDUCAÇÃO (MEC). Instituições de Educação Superior e Cursos Cadastrados, 2015. Disponível em: <http://emec.mec.gov. br/>. Acesso em: 2 mar. 2015.

BRASIL. MINISTÉRIO DA EDUCAÇÃO (MEC). Resolução CNE/CES 11, de 11 de março de 2002. Disponível em: <http://portal.mec.gov.br/cne/arquivos/ pdf/CES112002.pdf >. Acesso em: 28 fev. 2012.

BRASIL. MINISTÉRIO DA EDUCAÇÃO (MEC). Resolução no 2, de 17 de junho de 2010. Disponível em: $<$ http://portal.mec.gov.br/index. php?option=com co ntent\&view $=$ article\&id $=14917 \&$ Itemid $=866>$. Acesso em: 28 fev. 2012.

NRE - Núcleo de Real Estate. Perspectivas para o Setor do Real Estate Brasileiro no ano de 2014. Comitê de Mercado do NRE-Poli. Construção Mercado, São Paulo, n. 150, jan. 2014.

OLIVEIRA, Ana Beatriz de Figueiredo; SOUZA, Henor Artur. Sistemas construtivos industrializados nos cursos de graduação em Arquitetura e Engenharia Civil do Brasil. In: CONGRESSO BRASILEIRO DE EDUCAÇÃO EM ENGENHARIA, 42, 2014, Juiz de Fora. Anais... Juiz de Fora, 2014. CD-ROM.

RIBAS, Rovadávia Aline de Jesus. Avaliação das condições físico-construtivas e de desempenho de uma edificação estruturada em aço. Estudo de caso: Prédio da EM da UFOP. 2006. 187p. Dissertação (Mestrado em Engenharia Civil) - Escola de Minas, Universidade Federal de Ouro Preto. Ouro Preto, 2006.

SALAS, J. De los sistemas de prefabricación cerrada a la industrialización sutil de la edificación: algunas claves del cambio tecnológico. Informes de la Construcción, v. 60, n. 512 , p. $19-34,2008$. 
SANTIAGO, Alexandre K. O uso do sistema Light Steel Framing associado a outros sistemas construtivos como fechamento vertical externo não estrutural. 2008. 153p. Dissertação (Mestrado em Engenharia Civil) - Escola de Minas, Universidade Federal de Ouro Preto. Ouro Preto, 2008.
TAM, Vivian W. Y. et al. Towards adoption of prefabrication in construction. Building and Environment, v. 42, p. 3.642-3.654, 2007.

\section{DADOS DOS AUTORES}
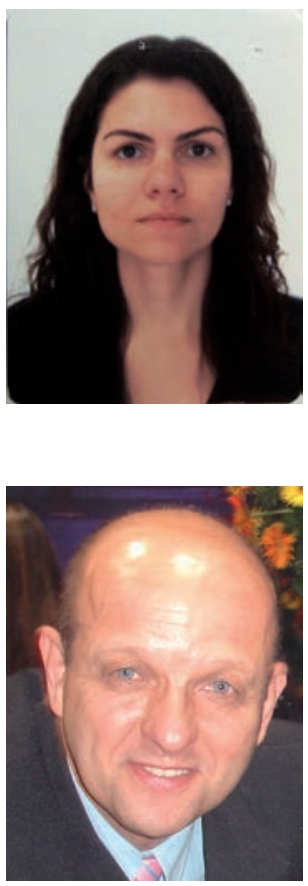

Ana Beatriz de Figueiredo Oliveira - Possui graduação em Arquitetura e Urbanismo pela Universidade Federal de Minas Gerais (UFMG, 2010), mestrado em Engenharia Civil, área de concentração em Construção Metálica, pela Universidade Federal de Ouro Preto (UFOP, 2013). Atualmente, é doutoranda em Arquitetura e Urbanismo pela Universidade de São Paulo (USP), área de concentração em Tecnologia da Arquitetura. Possui experiência na área de arquitetura e urbanismo, com ênfase em projeto de arquitetura, atuando principalmente nos seguintes temas: construção industrializada, construção metálica, processo de projeto.

Henor Artur de Souza - Possui graduação em Engenharia Mecânica pela Universidade Federal de Santa Catarina (UFSC, 1981), mestrado em Engenharia Mecânica, Ciências Térmicas, pela Universidade Federal de Santa Catarina (UFSC, 1985), doutorado em Engenharia Mecânica, Fluidos, pela Universidade Federal de Santa Catarina (UFSC, 1993). Atualmente, é Professor Titular da Universidade Federal de Ouro Preto (UFOP), atuando na graduação em Engenharia e Arquitetura e pós-graduação, no nível de mestrado e doutorado, no Programa de Pós-Graduação em Engenharia Civil-PROPEC. Possui experiência na área de engenharia mecânica, com ênfase em fenômenos de transporte, atuando principalmente nos seguintes temas: pesquisa básica e aplicada em fenômenos de transporte, ventilação em edificações, conforto ambiental, análise térmica de edificações, avaliação pós-ocupação em edificações estruturadas em aço (construção metálica). 